\title{
Carbon Deposit Formation in Normal-Pressure Electrical Discharges in Hydrocarbons
}

\author{
A.T. SOBCZYK* AND A. JAWOREK \\ Institute of Fluid Flow Machinery, Polish Academy of Science, Fiszera 14, 80-952 Gdańsk, Poland \\ The process of synthesis of carbon deposits from hydrocarbon vapours in low-current electrical-discharge \\ plasma was investigated in the paper. The carbon deposits were effectively synthesised in discharge of positive \\ polarity generated between a stainless steel needle and a plate made of nickel alloy, for the discharge current ranged \\ from $0.1 \mathrm{~mA}$ up to $3 \mathrm{~mA}$. The experiments were carried out at normal pressure in cyclohexane vapours with ar- \\ gon as carrier gas. The process of synthesis of carbon deposits was investigated using optical emission spectroscopy.
}

PACS numbers: 52.77.Fv, 52.80.Mg, 81.05.Lg

\section{Introduction}

Electrical discharges are used in various industrial processes such as, for example, surface modifications [1], sterilization [2], noxious compound decomposition [3], micro- and nanostructures synthesis [4-6], plasma etching and electrical-discharge machining [7], or flue gas cleaning [8]. For these processes, various forms of electrical discharges at both polarities are used: glow, streamers, or arc discharges. For effective generation of these discharges different wave forms of various frequencies were tested: direct-current (DC), alternating-current $(\mathrm{AC})$, radio-frequency $(\mathrm{RF})$, pulsed $(\mathrm{PD})$, or microwaves $(\mu \mathrm{W})$. Electrodes of different geometries used for gas ionization can be conductive or can be covered with a dielectric material. In the latter case, the dielectric barrier discharge (DBD), by $\mathrm{AC}$ or RF excitation, or back discharge (BD) by DC excitation are generated.

In this paper, we present investigations of the formation of carbon deposit on both electrodes in DC electrical discharge of positive polarity for various modes: glow discharge, streamer discharge and low-current arc discharge in the needle-plate electrode configuration.

\section{Experimental}

A schematic of experimental setup is shown in Fig. 1. The experiments were carried out in a reactor chamber of $0.1 \mathrm{dm}^{3}$ made of plexi glass, in atmosphere of argon and cyclohexane as carbon feedstock at ambient temperature and normal pressure. The hydrocarbon vapour was obtained by feeding cyclohexane to a heated flask where it evaporated. The concentration of hydrocarbon was controlled via adjusting the flow rate on a syringe pump dosing the cyclohexane, for a given flow rate of argon. From the flask, the gas mixture flowed to the reactor chamber with a flow rate of $8.2 \mathrm{dm}^{3} / \mathrm{h}$. The concentration of

* corresponding author; e-mail: sobczyk@imp.gda.pl hydrocarbons was changed from 1 to $5 \%$. The discharge was generated between a stainless steel needle and a plate made of nickel alloy. The diameter of the needle was $1 \mathrm{~mm}$, and the dimensions of the plate were $25 \times 40 \mathrm{~mm}$. The distance between the electrodes was $15 \mathrm{~mm}$. The discharge was supplied from a high voltage DC source SPELLMAN HV SL $600 \mathrm{~W} / 40 \mathrm{kV} / \mathrm{PN}$. The discharge current was stabilized via adjusting current limit on the voltage source in the range from $0.01 \mathrm{~mA}$ up to $3 \mathrm{~mA}$, and the overcurrent was limited with a series ballast resistance $5 \mathrm{M} \Omega$. The time of synthesis of the carbon fibers was $30 \mathrm{~s}$. The plasma processes during the discharge were analyzed by optical emission spectroscopy using Ocean Optics Maya2000 Pro with spectral range from 200 to $1100 \mathrm{~nm}$ and spectral resolution about $0.8 \mathrm{~nm}$ (spectroscope not shown, Fig. 1). The optical signals were transmitted to the spectrometer via solarization-resistant UV optical fiber (Ocean Optics P400-1-SR). After the discharge, the electrode's surface with the grown deposit was examined under a scanning electron microscope Zeiss EVO40.

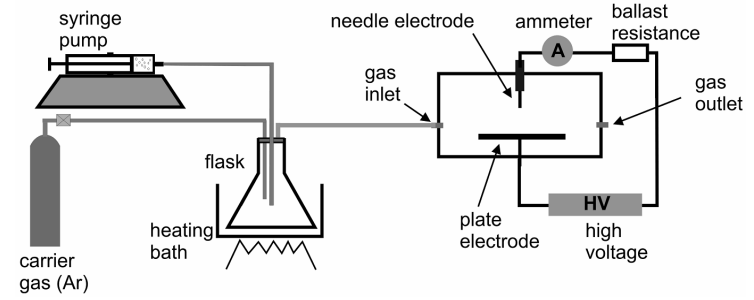

Fig. 1. Diagram of experimental setup.

\section{Results}

Current-voltage characteristics for positive polarity of the discharge in pure argon and a mixture of $4 \%$ of cyclohexane in argon are compared in Fig. 2. For low voltages, 
only faint discharge point at the needle tip was observed in argon and in the gas mixtures. The glow discharge developed into the interelectrode space with the supply voltage increasing. The range of the types of discharge are roughly marked in Fig. 2 with dotted line. For the argon mixture, the glow discharge started for lower supply voltages than for pure argon. For higher voltages, the current rapidly increased and the glow discharge switched into arc. In the gas mixture, the switching occurs for higher currents than in pure argon.

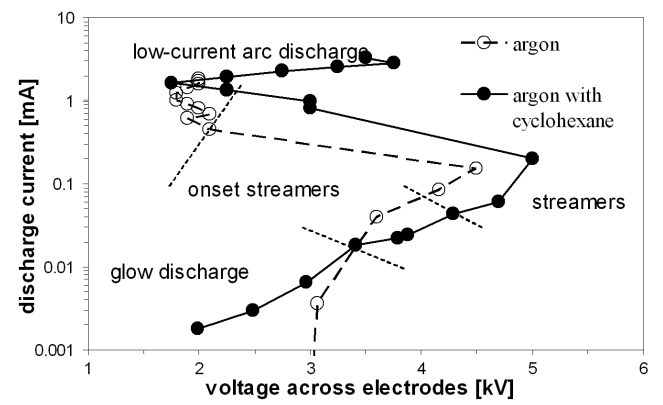

Fig. 2. Current-voltage characteristics of discharge in pure argon and mixture of $4 \%$ of cyclohexane in argon.

Figure 3 shows examples of carbon deposit, collected from the discharge needle, obtained after $30 \mathrm{~s}$ of the discharge and for three discharge currents: $0.5 \mathrm{~mA}, 1.4 \mathrm{~mA}$ and $2.4 \mathrm{~mA}$. The scanning electron microscopy (SEM) micrographs are shown for various magnifications. Figure $3 \mathrm{a}$ presents tip of the needle for the discharge current of $0.5 \mathrm{~mA}$. For this current, the carbon deposit on the needle tip was irregularly composed of $5-10 \mu \mathrm{m}$ grains. For $1.4 \mathrm{~mA}$ of the discharge current, the deposit was smoother but it was composed of many carbon nanofilaments. Close-up view of such deposit is shown in Fig. 3b. The diameter of these filaments was in the range from $85 \mathrm{~nm}$ to $130 \mathrm{~nm}$. It was observed that these nanofilaments have grown only after the needle tip was molten. However, the deposit was formed on the side wall of the needle, far from its molten tip. Region of growth of these nanofilaments suggest that direct bombardment of the anode by electrons was not favorable for deposition of the carbon because each deposit can be damaged by high-energy electrons. However, such structures can be still formed at side of the needle cone where the electric field is sufficiently high (about $10^{6} \mathrm{~V} / \mathrm{cm}$ ) to build up such structures, but the intensity of bombardment by electrons is weak.

For discharge current larger than $1.6 \mathrm{~mA}$, a carbon fiber had grown from the needle tip. With the discharge current increasing from $1.6 \mathrm{~mA}$ to $2 \mathrm{~mA}$, the fibers became longer after the same time of synthesis $(30 \mathrm{~s})$ which means that the growth rate was higher. A SEM micrograph of such fiber is shown in Fig. 3c. The morphology of carbon fibers in cross-section was homogeneous and their surface was smooth. For further increase in the discharge current, from $2.2 \mathrm{~mA}$ to $3 \mathrm{~mA}$, the length of car-

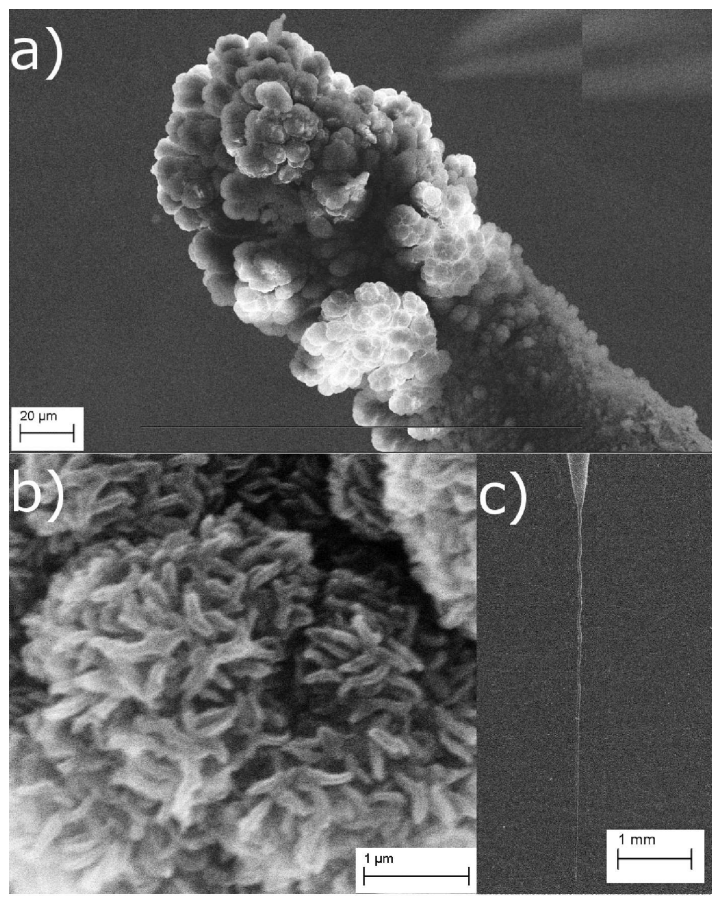

Fig. 3. SEM images of carbon deposit for various discharge currents: (a) $I=0.5 \mathrm{~mA}$; (b) $I=1.4 \mathrm{~mA}$; (c) $2.4 \mathrm{~mA}$ for $5 \%$ of cyclohexane in argon.

bon fiber became shorter after the same time of synthesis. The most intense growth of carbon fiber in our experimental conditions was obtained for a discharge current of about $2 \mathrm{~mA}$ by a voltage drop between the electrodes of $3.8 \mathrm{kV}$. In this case, the length of the carbon fiber was about $7 \mathrm{~mm}$, and its diameter about $35 \mu \mathrm{m}$. Similar maxima, with increasing discharge current, but for the process of thin carbon film deposition, were observed by Fedoseev et al. [9].

Figure 4 shows the emission spectra obtained for various discharge currents in $4 \%$ of cyclohexane in argon. The emission spectra can be roughly divided into two wide ranges. In the first range, from 300 to $690 \mathrm{~nm}$, the spectrum consists of numerous lines of molecules such as $\mathrm{CH}, \mathrm{C}_{2}, \mathrm{H}_{\alpha}$ and $\mathrm{H}_{2}$ being products or by-products of hydrocarbon pyrolysis. The highest line in this range is observed at $515.5 \mathrm{~nm}$ and corresponds to $\mathrm{C}_{2}$, specifically to the $(0,0)$ transition in the Swan System $\left(A^{3} \Pi_{\mathrm{g}}-\right.$ $\left.X^{\prime 3} \Pi_{\mathrm{u}}\right)$. Atomic hydrogen in alpha series was observed only in peak centered at $655.9 \mathrm{~nm}$. It can be supposed that atomic hydrogen has dissociated from cyclohexane. In the second spectral range, from $690 \mathrm{~nm}$ to $1100 \mathrm{~nm}$, only the lines of single-ionized argon were observed.

The intensity of these lines depends on the discharge current. For example, for higher discharge currents $(I=0.5 \mathrm{~mA})$ the intensity of $\mathrm{C}_{2}, \mathrm{CH}$ and $\mathrm{H}_{\alpha}$ lines are larger than for a current of $0.09 \mathrm{~mA}$. Higher intensity of these lines is due to higher current of the discharge and increasing number of electrons colliding with molecules. The intensity of lines of single ionized argon is higher 


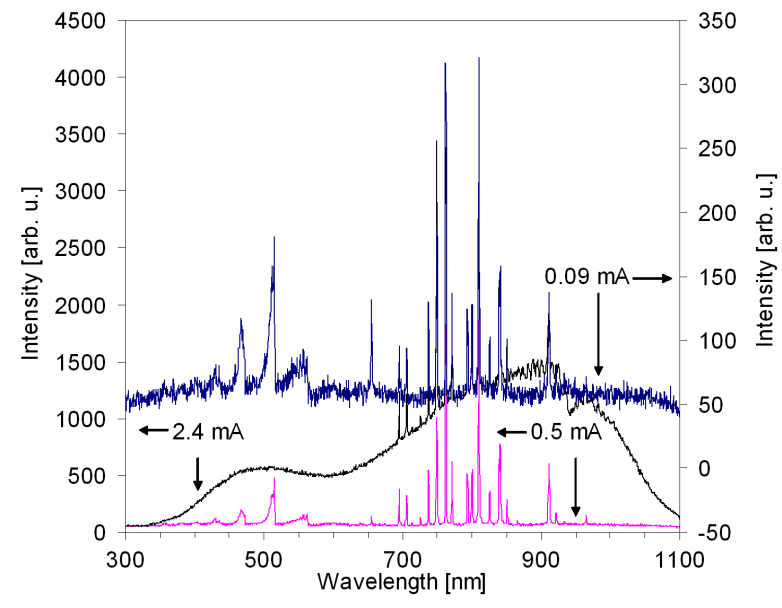

Fig. 4. Emission spectra of discharges in $4 \%$ of cyclohexane in argon for various discharge currents. Left intensity scale for 0.5 and $2.4 \mathrm{~mA}$, right intensity scale for $0.09 \mathrm{~mA}$.

than lines of dissociated products of cyclohexane. It was estimated from the current-voltage characteristics that power of the discharge at $0.5 \mathrm{~mA}$ was 9 times higher than for $0.09 \mathrm{~mA}$.

The discharge spectrum significantly changes for currents at which the arc discharge is generated. For example, for a discharge current of $2.4 \mathrm{~mA}$, the two continuum spectra, from 350 to $700 \mathrm{~nm}$ and from about 500 to 1100 , resembling black-body radiation, have been recorded that can be attributed to emission from the carbon deposit (carbon fiber tip) heated by the discharge current. The intensity of continuum radiation increases with the discharge current. Continuum emission from 350 to $700 \mathrm{~nm}$ is an effect of overlapping of various band systems of $\mathrm{C}_{2}$ and other products of cyclohexane dissociation such as $\mathrm{CH}, \mathrm{CH}^{+}, \mathrm{C}_{4} \mathrm{H}_{2}^{+}$etc. The intensity of continuum radiation increases with time of deposition indicating that main source of radiation are various band systems of $\mathrm{C}_{2}$ [10] sputtered from carbon fiber. This result can indirectly explain a decrease of carbon fiber growth rate for higher discharge currents causing intense sputtering of deposited carbon from its tip. Continuum spectrum from 500 to $1100 \mathrm{~nm}$ is an effect of thermal emission from carbonaceous particles. It can be noticed that intensity of lines of ionized argon for the discharge current of $2.4 \mathrm{~mA}$ is 10 times stronger than for $0.09 \mathrm{~mA}$.

\section{Conclusions}

In our experiments, the synthesis of carbon deposit in low-current electrical discharge of positive polarity in point-plane electrode geometry, in cyclohexane as the carbon feedstock and with argon as carrier gas was investigated. The discharge current varied from $0.01 \mathrm{~mA}$ to $3 \mathrm{~mA}$. In the discharge, different carbon deposits were obtained: carbon nanofilament or carbon fiber, depending on the discharge current. The emission spectrometry was used in order to better understand the processes leading to various carbon deposits formation. Higher intensity of $\mathrm{C}_{2}, \mathrm{CH}$ and $\mathrm{H}_{\alpha}$ lines is due to higher current of the discharge and increasing number of electrons colliding with molecules. There was observed a continuum radiation whose intensity increased with the discharge current. This result can provide a probable mechanism of decreasing growth rate of carbon fiber with increasing discharge current as caused by more intense sputtering of deposited carbon from the tip of fiber.

\section{Acknowledgments}

The paper was supported by Polish Ministry of Science and Higher Education within the project No. 0104/B/T02/2007/32.

\section{References}

[1] G. Borcia, C.A. Anderson, N.M.D. Brown, Plasma Sources Sci. Technol. 12, 335 (2003).

[2] M. Moreau, N. Orange, M.G.J. Feuilloley, Biotechnol. Adv. 26, 610 (2008).

[3] D.I. Slovetsky, Pure Appl. Chem. 60, 753 (1988).

[4] Handbook of Nanotechnology, Ed. B. Bhushan, Springer-Verlag, Berlin 2004, p. 39.

[5] A. Huczko, Appl. Phys. A 74, 617 (2002).

[6] A.T. Sobczyk, A. Jaworek, E. Rajch, M. Sozanska, Solid State Phenom. 140, 103 (2008).

[7] B.B. Pradhan, M. Masanta, B.R. Sarkar, B. Bhattacharyya, Int. J. Adv. Manuf. Technol. 41, 1094 (2009).

[8] A. Jaworek, A. Krupa, T. Czech, J. Electrostatics 65, 133 (2007).

[9] D.V. Fedoseev, Yu.N. Tolmachev, I.G. Varshavskaya, V.L. Bukhovets, Diamond Relat. Mater. 5, 429 (1996).

[10] A. Qayyuma, M.N. Akhtar, J. Eur. Phys. D 12, 181 (2000). 